\title{
Maternal and Fetal Outcomes in Previous One Cesarean Pregnancies
}

\author{
Authors \\ Dr Siddesh Mahadev Iyer ${ }^{1}$, Dr Varsha Ajay Hariani ${ }^{2}$ \\ ${ }^{1}$ MBBS, DGO, DNB OBGY, Registrar, Harilal Bhagwati Municipal General Hospital, Borivali West \\ Mumbai \\ ${ }^{2}$ MBBS, MD OBGY, Hon. Asst Prof. Harilal Bhagwati Municipal General Hospital, Borivali West, Mumbai \\ Shri Harilal Bhagwati Municipal General Hospital, Borivali West, Mumbai \\ Corresponding Author \\ Dr Siddesh Mahadev Iyer \\ 602 Awing Park Side 2, Raheja Estates, Kulupwadi, Borivali East, Mumbai 400066 \\ Telephone number: 9223524599 \\ Email: siddeshiyer@gmail.com

\begin{abstract}
A previous caesarean delivery does cast a shadow over the outcome of future pregnancy and labour, main fear being catastrophic uterine rupture. Vaginal birth or trial of labour after previous caesarean delivery has become one of the most remarkable and yet controversial changes in obstetric practice. This is being practiced as one of the strategies to control the alarming rise in rate of caesarean sections. Inspite of uterine rupture being a known complication, the trial of labour or scar (The word, once only used for cephalo-pelvic disproportion cases) of vaginal birth after caesarean (VBAC) is a well established standard practice of care. We studied the incidence incidence of vaginal delivery after one caesarean, incidence of repeat caesarean, its indications, and factors affecting maternal and fetal outcome.
\end{abstract}

Keywords: previous cesarean, vbac,

\section{Introduction}

The interest in vaginal births after caesarean section has been rekindled as the rates of primary caesarean sections have been ever increasing. However deciding when to attempt VBAC (vaginal birth after caesarean)is a major decision and should be based on careful selection of patients after thorough counselling, estimation of patients' risk and strict adherence to guidelines for managing labour in units where facilities for immediate surgery exist if complications arise. Our objective was to study the incidence of vaginal delivery after one caesarean, incidence of repeat caesarean, its indications, and factors affecting maternal and fetal outcome.

\section{Material and methods}

Retrospective study was carried out from April 2012 to March 2013. Women with one previous lower segment caesarean were included. Patients with previous two caesareans or previous classical or $\mathrm{T}$ shaped caesareans were excluded. Data was collected from the medical records department after necessary permission. 


\section{Results}

127 out of 300 (43\%) had vaginal delivery

$157(52 \%)$ had repeat emergency LSCS

13 (4\%) had elective repeat caesarean.

48 out of 170 total repeat caesareans $(28 \%)$ were for cephalopelvic disproportion

29 out of $170(17 \%)$ were for post dated pregnancy

22 out of $170(13 \%)$ were for foetal distress in labour

261out of 300 (87\%)of women belonged to 18-30 year age group, the mean age was 26.5 years.

The incidence of vaginal delivery was lesser if the age of the patient was more than 30 years

272 out of 300 (91\%) of women had interconceptional period more than two years of which 121(44\%) delivered vaginally. The chances of vaginal delivery were higher if the interconceptional period was more than two years (statistically significant).

$63 \%$ who delivered vaginally had previous VBAC. (statistically significant).

172 out of 300 babies weighed $<3 \mathrm{kgs}$ of which 87 $(51 \%)$ had a vaginal delivery. (statistically significant).

29 out of 172 (17\%) had adhesions

$4(2 \%)$ had scar dehiscence

$3(1 \%)$ had a rupture.

Rest had normal findings.

No maternal mortality was seen.

17 out of $300(6 \%)$ babies were admitted to NICU and $3(1 \%)$ perinatal deaths took place.

\section{Discussion}

The American College of Obstetricians and Gynecologists (1988) recommended that most women with one previous low transverse caesarean delivery should be counseled to attempt labour in a subsequent pregnancy ${ }^{[1]}$.

A variety of reasons have improved the safety of caesarean section and increased the indications for its performance, like emergence of specialists in obstetric anesthesia, improvement in blood transfusion, antibiotics, thromboprophylaxis and surgical techniques. There are now social and medico-legal expectations of perfect perinatal outcome which has undoubtedly influenced obstetric care. Advanced maternal age, infertility and assisted reproductive technologies have led to rise in number of so called "premium" pregnancies. Although not common there is increase demand for elective caesarean section for fear of labour and vaginal delivery and perceived benefits of reducing rare fetal risks in labour and long term sequelae of pelvic floor damage. The other responsible factors are wider use of repeat LSCS in cases with previous caesarean delivery, rising rates of induction of labour and failure of induction, decline in operative vaginal (Mid forceps, Vacuum) delivery, manipulative vaginal delivery (Rotational forceps)and vaginal breech delivery, adoption of small family norm- neither the obstetrician, nor the patients are ready to accept any risk of abnormal labourwider use of electronic fetal monitoring and increased diagnosis of fetal distress.

\section{Factors affecting the outcome of pregnancy}

Kambo, Bedi et al (2002) analyzed the information obtained on total number of normal and caesarean deliveries during 1993-1994 and 1998-1999 from 30 medical colleges and found that among the 7,017 cesarean section cases, $42.4 \%$ were primigravidas, $20.8 \%$ were referred including $8 \%$ with history of interference, $66 \%$ were booked cases, period of gestation was less than 37 weeks in $21.7 \%$ and in $18 \%$ the surgery was elective. Major indications for caesarean section included dystocia (37.5\%), fetal distress with or without meconium aspiration (33.4\%), repeat section $(29.0 \%)$, malpresentation $(14.5 \%)$ and PIH $(12.5 \%)^{[2]}$.

In a study of frequency and indications of caesarean section in a tertiary care hospital of Uttarakhand, India, Singh AK et al (2011) found that the most common indication of caesarean section was fetal distress (32.8\%) followed by previous cesarean section with scar tenderness $(24.3 \%)^{[3]}$.

Kayani et al 2005 reviewed the literature to elucidate the international stance on induction of 
labour in women with previous caesarean section and noted that there was no evidence to suggest that current induction methods were less effective in women with previous caesarean section. However, there is no question that induction of labour is associated with higher risk of uterine rupture, but quantifying this risk remains elusive [4].

There should be a careful scrutiny of the previous operative report. If there was any marked extension of one of the both angles, or a ' $\mathrm{T}$ " extension into the upper uterine segment, these scars are best not subjected to labour. Previous rupture of any type of uterine scar in previous pregnancy is obviously a contraindication to subsequent labour. ${ }^{[5,6]}$

If the women had previous vaginal delivery, either before or after the caesarean section, her chances of successful and safe VBAC are enhanced. This is one of the positive factors in favour of trial of labour for vaginal delivery.

One of the most common reasons for primary caesarean section is dystocia or cephalopelvic disproportion, although a true diagnosis of the latter is rare. These diagnosis are not necessarily a recurrent indication and many wil labour and deliver successfully after previous caesarean section for these indications.

Pregnancy and delivery within 12 months of a previous caesarean section may be associated with an increased risk of scar rupture in this pregnancy. Trial of vaginal delivery can only be undertaken in the hospital which has immediately available midwifery, nursing, anaesthesia and obstetric staff along with appropriate operative theatre, laboratory and blood transfusion services. There are number of 'SOFT FACTORS' which may influence the decision. These include maternal age, secondary infertility, the desire for more pregnancies and previous maternal morbidity

Trial of labour is associated with reduced risk of morbidity for the mother compared with those of a repeat caesarean section. However the risk of major complications like hysterectomy, uterine rupture, or operative injuries were fivefold greater in women, whose attempt at vaginal delivery failed. Dadhwal V et al reported $2.56 \%$ uterine rupture rate among 156 patients with prior history of caesarean section who were subjected to trial of labour $^{[7]}$.

Studies have shown during trial of labour in a previous caesarean delivered women the condition of fetus may get compromised. However the incidences are very less. Landon and collabourators, $2004{ }^{[8]}$ reported that the rates of stillbirth and hypoxic ischemic encephalopathy were greater in the trial of labour arm.

\section{Conclusion}

$42 \%$ delivered vaginally after previous one caesarean section, signifying that trial of labour can be given to previous caesareans without any obvious cephalopelvic disproportion.

Factors influencing the outcome of trial of labour are history of vaginal delivery, maternal age, weight of the baby and the interconceptional period.

Smaller babies and older scars are more favourable for VBAC.

VBAC rates have ebbed and flowed from virtually none to a significant increase to a current decreasing trend. The essence of selection for and management of VBAC is to avoid extremes.

As the risks to the women have progressively diminished, LSCS has been found to be justifiable for ever widening clinical indications. As more and more women enter second and subsequent pregnancies with uterine scar it is important to emphasise the long-term potential for serious consequences of caesarean section, which are not often perceived by a short-sighted focus on the immediate decision concerning mode of delivery.

To conclude, an expectant attitude and individualization with respect to the management of pregnancy and labour in patients who had one caesarean section is not only justifiable, but represents sound and conservative obstetrical practice. 


\section{References}

1. American College of Obstetricians and Gynecologists. ACOG 4. Practice bulletin no. 54. Vaginal birth after previous caesarean delivery. Obstetrics and Gynecology, 2004, 104:203-212

2. Kambo I, Bedi N, Dhillon BS, Saxena NC. A critical appraisal of cesarean section rates at teaching hospitals in India. Int $\mathbf{J}$ Gynaecol Obstet. 2002 Nov; 79(2):151-8

3. Singh AK et al 2011. Study of Frequency and Indications of Caesarean Section in a Tertiary Care Hospital of GarhwalUttarakhand, India. Jour of Research in Medical Education \& Ethics: 2011, Vol: 1(2):122-4

4. Kayani SI, Alfirevic Z: Uterine rupture after induction of labour in women with previous caesarean section. BJOG 2005; 112: 451

5. Nielsen TF, Otterblad Olausson $P$, Ingemarsson I. The caesarean section rate in Sweden: the end of the rise. Birth 1994;21:1 (March).

6. D.C.Dutta's Text book of obstetrics. Operative obstetrics. New Central Book Agency (P) Ltd London. $7^{\text {th }}$ edition.2011; Pages: 588-608

7. Dadhwal V et al. vaginal birth after caesarean delivery: variables affection outcome. JK science. Jan-mar 2003.Vol 5 (1):11-14

8. Landon MB, Hauth JC et al. Maternal and Perinatal outcomes associated with trial of labour after previous caesarean delivery. Eng J Med.2004;351:2581. 